\title{
ОСОБЕННОСТИ УПРАВЛЕНИЯ МЕЖДУНАРОДНЫМИ РЕЗЕРВНЫМИ АКТИВАМИ В РОССИИ
}

\author{
(C) 2020 Швецова Анна Алексеевна \\ Российский университет дружбы народов (РУДН), Россия, Москва \\ E-mail: anna.shvetsova.ru@yandex.ru
}

Тенденцией последнего десятилетия в условиях нестабильного многополярного мира является активная деятельность властей ведущих стран мира по обеспечению устойчивости национальных экономик к воздействию внешних потрясений. Одним из инструментов признается процесс управления международными резервами. Исследование особенностей российской модели представляет особую значимость для разработки дальнейшей концепции управления резервами на современном этапе.

Ключевые слова: международные резервные активы, золотовалютные резервы, управление международными резервами, уровень достаточности резервов.

В течение последних лет наблюдается общемировой тренд на устойчивый рост объема международных резервов, которые за период с 2005 по 2020 гг. увеличились более чем в 3 раза и на начало 2020 составили 11,8 трлн. долл. США, причем больший прирост резервных активов наблюдался среди развивающихся стран (5,5 трлн. долл. США или почти 250\%) [10]. В то же время мировой ВВП увеличился лишь в 1,8 раз [14].

Лидерами по объему накопленных международных резервов по состоянию на 1 января 2020 года являются: Китай (3400 млрд. руб.), Япония (1387 млрд. руб.) и Швейцария (851 млрд. руб.) [11].

Россия к началу 2020 года устойчиво занимала четвертое место. Объем российских резервных активов за период с 2005 по 2020 гг. увеличился в 4,5 раза [4]. После случаев существенного снижения величины международных резервов на фоне глобального кризиса 2008-2009 гг. и в результате введения экономических санкций против России в 2014 году денежные власти придерживаются политики активного резервирования национальной экономики. Кроме того, прирост объема резервного портфеля обусловлен увеличением его золотой составляющей, которая остается одной из самых высоких среди развивающихся государств.

Накопление золотовалютных резервов разными странами можно объяснить стремлением национальных экономик минимизировать возможные риски и обеспечить способность исполнять свои внешние обязательства в обозримой перспективе. Большой теоретический вклад в исследование проблемы определения уровня достаточности золотовалютных резервов внесли А.Бен-Бассет, П.Гвидотти, А.Гринспен, В.Редди, Д.Родрик. Концепции управления международными резервами России в контексте обеспечения национальной экономической безопасности отражены также в работах В.К.Сенчагова, Е.А.Звоновой, А.Н.Сухарева. Отмечается, что, при прочих равных условиях, национальная экономика, в которой величина резервирования чрезвычайно мала или отсутствует вовсе, будет более уязвима и подвержена воздействию внешних угроз.

Отечественные ученые В.В.Попов и В.М. Полтерович описали зависимость между увеличением национальных накоплений и высокими темпами экономического роста, что обуславливает лидирующие позиции азиатских стран по величине накопленных международных резервов. Только на Китай приходится 30\% от общемирового объема резервных активов (не считая $4 \%$ в Гонконге), а в «десятку» лидеров входят также Япония, Республика Корея и Сингапур. В своих трудах ученые выявили тесную статистическую взаимосвязь между темпами роста международных резервов и ключевыми макроэкономическими показателями, такими как темпы роста ВВП, доля инвестиций в ВВП и темпы роста прямых иностранных инвестиций. Своими исследованиями авторы доказывают действенность политики накопления резервов как универсального средства инициации экономического роста, преимущественно в развивающихся странах [7].

Важное значение для совершенствования мировой практики управления резервными активами также имеют методические разработки и рекомендации Международного валютного 
фонда.

Указанные исследования применимы и к российской модели управления международными резервами. Тенденция активного накопления резервных активов России в последние годы сопровождается последовательным процессом изменения валютной политики государства, предполагающей диверсификацию резервного портфеля путем сокращения доли долларовых активов и увеличения вложений в золото и другие международные валюты. Вместе с тем, процесс дедолларизации в рамках диверсификации российских резервов представляется достаточно спорным и при неправильно проводимой денежными властями валютной политике может привести к неблагоприятным последствиям. В этой связи проблема оптимизации структуры и оценки уровня достаточности резервных активов в условиях неопределенности конъюнктуры на внешних рынках признается особенно актуальной и значимой для разработки дальнейшей концепции управления международными резервами России с точки зрения вопроса экономической безопасности государства.

Понятие и сущность международных резервов

Понимание сущности международных резервов сводится к определению, предложенному Международным валютным фондом (МВФ), в соответствии с которым резервными активами признаются «внешние активы, имеющиеся в свободном распоряжении органов денежнокредитного регулирования и контролируемые ими в целях удовлетворения потребностей в финансировании платежного баланса, проведения интервенций на валютных рынках для оказания воздействия на валютный курс и в других соответствующих целях» [9, с. 143]. Российские резервные активы находятся в распоряжении и под контролем Банка России и Правительства Российской Федерации.
Существуют определенные требования к активам, формирующим портфель международных резервов государства. Особое внимание при этом уделяется уровню ликвидности и надежности инструментов резервирования. Требование высокого уровня ликвидности обусловлено тем, что, при возникновении острой потребности в иностранной валюте, резервы должны быть доступны для использования органами денежнокредитного регулирования в очень короткий срок. Кроме того, резервный портфель должен отличаться минимальным риском вложений средств, а также конвертируемостью, стабильностью и низкой волатильностью курсов валют, в которые деноминированы резервные активы.

Структура международных резервных активов отдельных стран может различаться. Вместе с тем, резервный портфель формируется как правило из четырех основных составляющих, в число которых входят монетарное золото, резервная позиция в МВФ, специальные права заимствования и прочие резервные активы, включающие в себя, в том числе, наличную иностранную валюту, депозиты и долговые ценные бумаги, выпущенные нерезидентами.

Особенности управления резервами в России и международный опыт

Структура портфеля международных резервов России по состоянию на 1 января 2020 года [4] представлена в табл. 1.

Результаты анализа динамики изменений российских резервов в течение последних 15 лет (Рисунок 1) свидетельствуют о преобладании в портфеле иностранной валюты, доля которой варьируется от 77\% до 98\% совокупного объема международных резервов России за рассматриваемый период [4]. Вместе с тем, доля иностранной валюты с каждым годом снижается и на сегодняшний день является минимальной величиной.

Таблица 1. Международные резервы Российской Федерации (на 01.01.2020)

\begin{tabular}{|l|c|c|}
\hline & Значение (млн. долл. США) & Доля (\%) \\
\hline Всего, в том числе: & 554359 & 100,00 \\
\hline Валютные резервы & 443983 & 80,09 \\
\hline Иностранная валюта & 433297 & 78,16 \\
\hline Счет в СДР & 6717 & 1,21 \\
\hline Резервная позиция в МВФ & 3970 & 0,72 \\
\hline Монетарное золото & 110376 & 19,91 \\
\hline
\end{tabular}




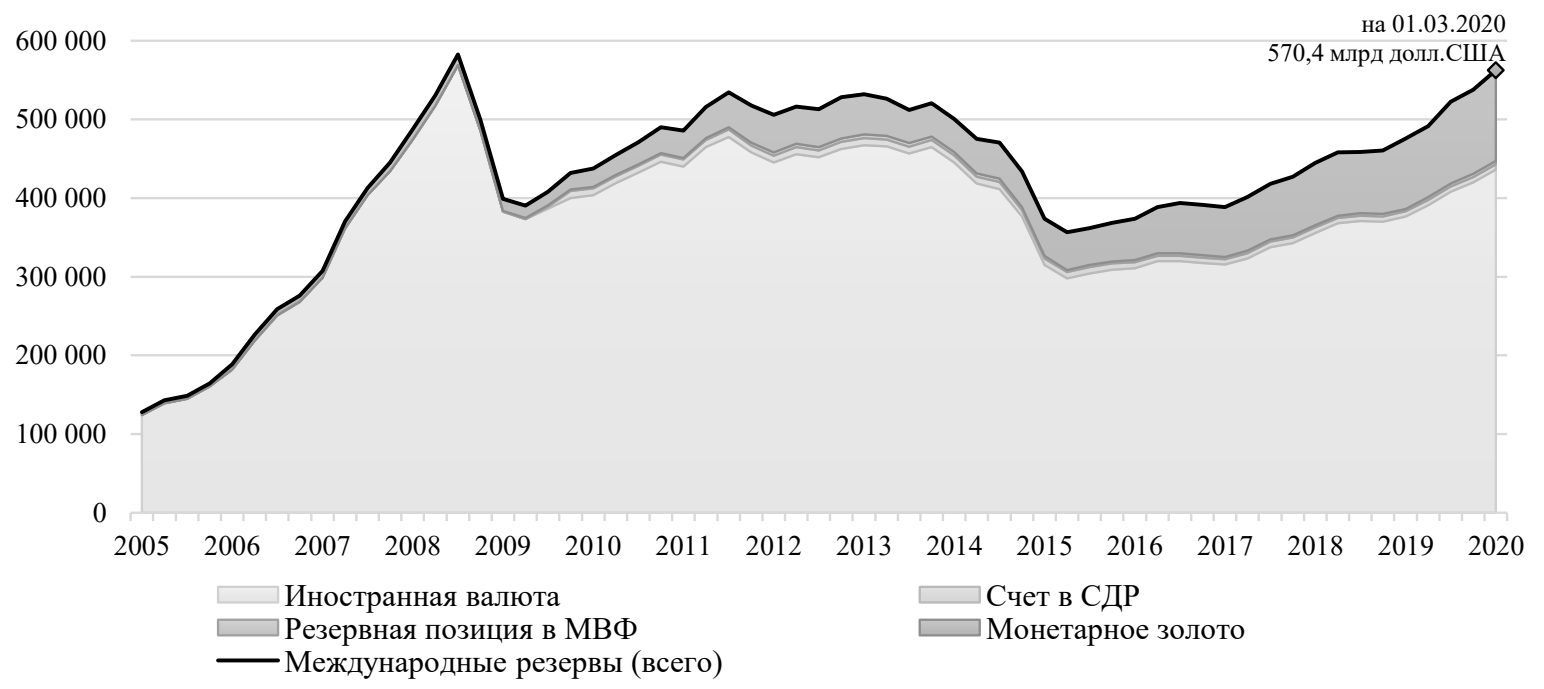

Puc. 1. Структура международных резервов России (млн. долл. США)

Источник: построено автором по данным Центрального банка Российской Федерации.

Такая тенденция объясняется смещением национальных накоплений в сторону наращивания золотых запасов в структуре портфеля. Резервные активы в форме монетарного золота представляют собой принадлежащие Банку России и Правительству Российской Федерации стандартные золотые слитки и монеты с чистым содержанием металла не ниже 995 пробы. В данную категорию включают как золото в хранилищах, так и находящееся в пути и на металлических счетах ответственного хранения, вне зависимости от местонахождения счета.

На сегодняшний день основными держателями желтого металла являются Соединенные Штаты (на начало 2020 года - 8133,5 т), Германия (3366,5 т), Италия $(2451,8$ т), Франция $(2436,1$ т) и Китай $(1948,3$ т). Россия входит в «пятерку» стран-лидеров, держа в своих хранилищах золото в размере $2271 \mathrm{~T} \mathrm{[12].}$

В 2018 году Банк России стал крупнейшим покупателем золота, увеличив его запасы на рекордные 8,8 млн. тройских унций или 274 т (42\% всех закупок золота центральными банками мира за 2018 год). Такие закупки стали одним из составляющих кампании по дедолларизации российской экономики. В настоящее время доля золота в международных резервах страны достигла исторического максимума в размере 119,8 млрд. долл. США или 21,3\% от объема резервного портфеля (по состоянию на 1 апреля 2020 года), тогда как на начало 2017 года этот показатель равнялся 16\% [4].

Среди преимуществ золотой составляющей резервного портфеля выделяют то, что в слу- чае возникновения и реализации тех или иных рисков для финансовой устойчивости экономики или даже наступления финансового кризиса золотые запасы могут послужить важным дополнительным фактором, обеспечивающим ликвидность национальной валюты - рубля, а также повышения доверия к российской финансовой системе в целом.

Однако, признанный одним из самых стабильных и наиболее надежных активов в настоящее время теряет свою актуальность. Так, Банком России в 2019 году были существенно сокращены закупки монетарного золота в целях пополнения международных резервов (на $42 \%$ в сравнении с 2018 годом) [8]. Кроме того, по информации регулятора, с 1 апреля 2020 года закупка золота на внутреннем рынке драгоценных металлов полностью приостановлена на неопределенный срок.

По сравнению с валютными активами золото является хоть и надежным, но менее доходным и распространенным инструментом, поэтому преобладающая доля в международных резервах отводится именно активам в иностранной валюте.

Как и в большинстве стран мира, резервный портфель России представлен главным образом валютными активами, 97,6\% из которых приходится на иностранную валюту. За последние 10 лет доля иностранной валюты составляла в среднем 85\% от объема портфеля [4]. Это обусловлено тем, что валютные резервы, представленные банковскими депозитами и вложениями в иностранные ценные бумаги, признаются более 
гибким и доходным инструментом среди прочих составляющих национальных накоплений.

Согласно отчету Currency Composition of Official Foreign Exchange Reserves (COFER), подготавливаемому Департаментом статистики МВФ, распределение международных резервных активов в разрезе валютной структуры по состоянию на 31 декабря 2019 года [10] выглядит как показано в табл. 2.

Представленные данные подтверждают, что доллар США является основной резервной валютой мира: доля активов, деноминированных в долларах США, составляет более 60\%. Вторая по значимости и широте распространения резервная валюта - евро (20,5\%). После введения в 1999 году евро частично «унаследовал» долю в расчетах от немецкой марки, французского франка и прочих европейских валют, и с тех пор его доля с каждым годом увеличивается. «Тройку» лидеров замыкает японская иена $(5,7 \%)$, которой уступает одна из самых значимых резервных валют XVIII-XX вв.- фунт стерлингов с долей 4,6\%.

Динамика изменений международных резервов стран мира в разрезе валют за период 2005-2019 гг. продемонстрирована на Рисунке 2.

На представленной диаграмме можно проследить тенденцию хранения большей части национальных накоплений стран мира в долларовых активах (преимущественно в суверенных долговых ценных бумагах - казначейских облигациях США), что объясняется высокой степенью надежности данного инструмента и возможностью получения фиксированного дохода.

Стоит отметить, однако, что получение дохода не является приоритетной целью управления портфелем резервных активов. Среди ключевых мотивов формирования международных резер- вов [3, с. 12] выделяют следующие:

- финансирование дефицита платежного баланса, для которого международные резервы являются балансирующей статьей (характерно для стран-экспортеров сырьевых ресурсов в связи с высокой волатильностью цен на мировом рынке и, как следствие, угрозами возникновения существенного дисбаланса внешней торговли в короткие промежутки времени);

- поддержание курса национальной валюты посредством валютных интервенций органов финансового регулирования в целях снижения рисков при проведении внешних операций (особенно важно для экономик, в которых национальная валюта не является полностью конвертируемой, или стран с режимом фиксированного обменного курса);

- обеспечение международной платежеспособности экономики, то есть гарантии того, что государство будет способно выполнять свои внешние обязательства, в том числе по обслуживанию внешнего долга, даже в случае резкого сокращения экспортной выручки и прочих поступлений иностранного капитала.

Управление валютными активами Российской Федерации осуществляется Банком России посредством распределения резервов по валютам в целях обеспечения оптимального сочетания ликвидности, сохранности и доходности, с учетом имеющихся обязательств в иностранной валюте. В целях нивелирования валютных рисков регулятор, во-первых, определяет перечень так называемых разрешенных валют (валюты, в которых деноминированы резервные валютные активы) и, во-вторых, устанавливает целевые доли валют в чистых валютных активах. При этом, должны быть минимизированы или ис-

Таблица 2. Валютная структура международных резервов

\begin{tabular}{|l|c|c|}
\hline & Значение (млн. долл. США) & Доля (\%) \\
\hline Всего & $\mathbf{1 1 8 2 9 5 4 4 , 2 5}$ & $\mathbf{1 0 0 , 0 0}$ \\
\hline Размещенные резервы & 11078428,81 & 93,65 \\
\hline Доллар США & 6745646,41 & 60,89 \\
\hline Евро & 2275945,81 & 20,54 \\
\hline Японская иена & 631439,79 & 5,70 \\
\hline Фунт стерлингов & 511814,75 & 4,62 \\
\hline Китайский юань & 217672,83 & 1,96 \\
\hline Канадский доллар & 207978,37 & 1,88 \\
\hline Австралийский доллар & 187311,06 & 1,69 \\
\hline Швейцарский франк & 16981,46 & 0,15 \\
\hline Другие валюты & 283638,33 & 2,71 \\
\hline Неразмещенные резервы & 751115,44 & 6,35 \\
\hline
\end{tabular}




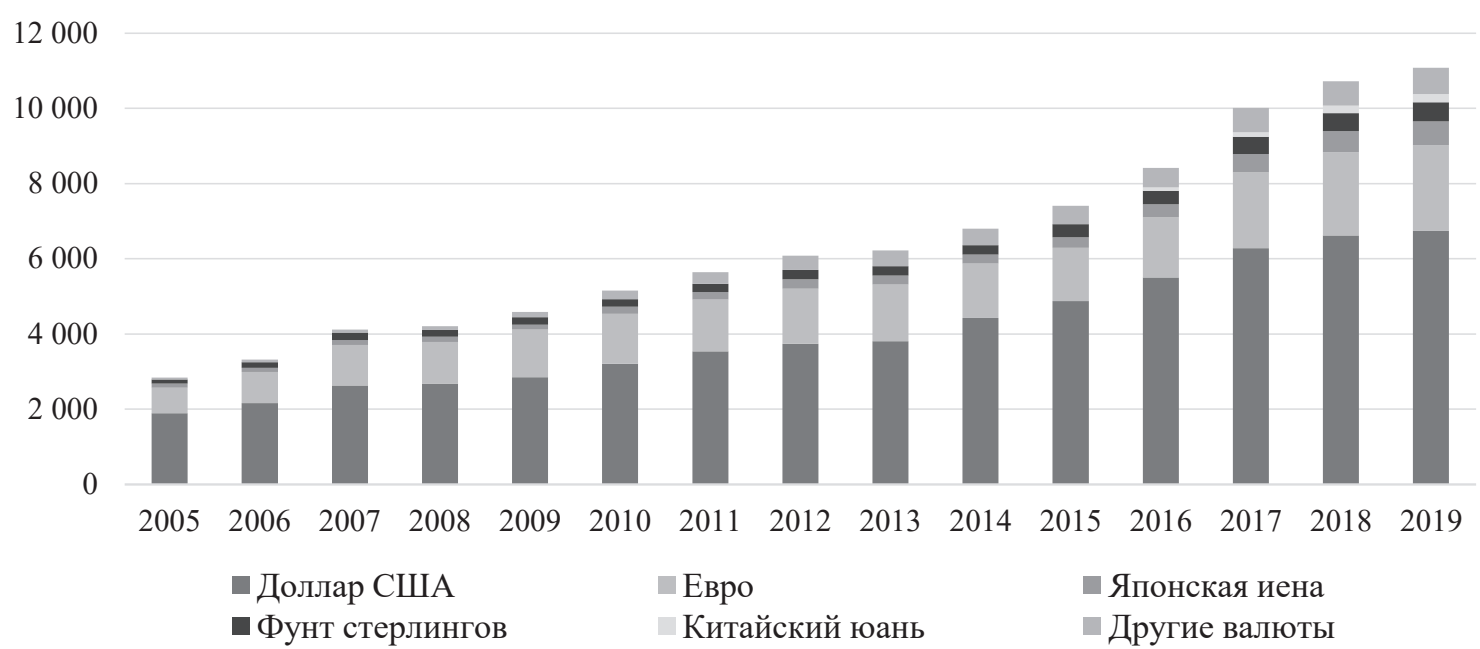

Puc. 2. Валютная структура международных резервов (млрд. долл. США) Источник: построено автором по данным Международного валютного фонда.

ключены риски потерь от переоценки валютных активов вследствие колебаний валютного курса и волатильности на мировом финансовом рынке.

По состоянию на 1 октября за период 20172019 гг. валютная структура резервного портфеля России менялась как показано на рисунке. 3.

Отмечается существенное снижение доли долларовых активов в российском резервном портфеле - в два раза за период 2017-2018 гг., прежде всего в пользу юаня и евро. По данным Банка России, на конец июня 2018 года доля доллара в международных резервах страны достигла исторического минимума $21,8 \%$ по сравнению с 43,7\% в марте [6], даже несмотря на то, что структура российских резервов в целом отличается меньшей долей доллара США по сравнению с общемировой тенденцией (доля долларовых активов в общей величине мировых валютных резервов колеблется в пределах 60-80\%).
Данное обстоятельство нашло отражение в ежегодном обзоре The international role of the euro, опубликованном Европейским центральным банком (ЕЦБ) в июне 2019 года [13]. Регулятором отмечено, что доля доллара в мировых валютных резервах в 2018 году сократилась до минимальных 61,7\% с момента создания зоны евро. В качестве одной из причин ЕЦБ назвал продажу развивающимися странами, многие из которых являются крупнейшими держателями резервов, своих активов, деноминированных в долларах США. Вследствие повышенной волатильности на финансовых рынках эти страны начали проводить валютные интервенции для стабилизации курса национальных валют, и в период с марта по сентябрь 2018 года они продали деноминированные в долларах резервы, в совокупности оцениваемые в 200 млрд. долл. США.

Другим фактором, повлиявшим на снижение доли доллара в резервах, ЕЦБ назвал диверси-

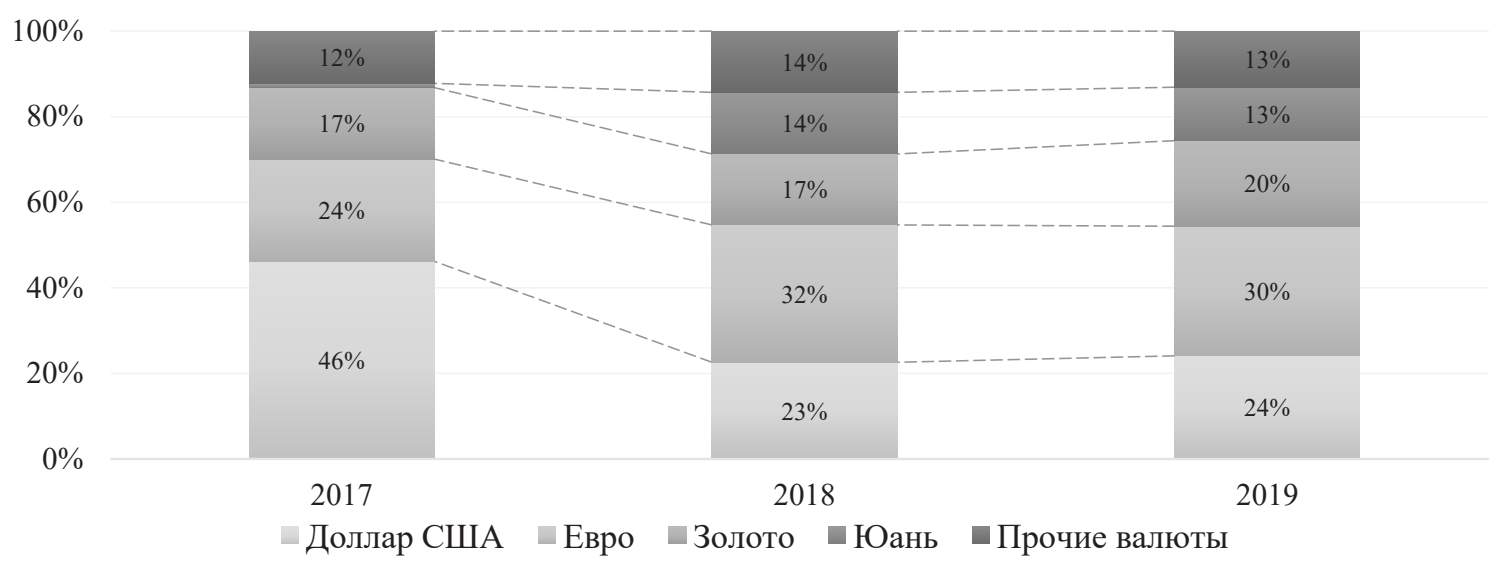

Puc. 3. Распределение международных резервов России

Источник: построено автором по данным Центрального банка Российской Федерации. 
фикацию центральными банками, в особенности Банком России, своих резервных портфелей из-за опасений введения односторонних санкций. В современных условиях вложения в казначейские обязательства США представляются достаточно спорными: в контексте финансовоэкономических санкций зарубежных стран в отношении Российской Федерации преобладание долларовых активов в валютной структуре международных резервов создает неблагоприятную ситуацию для экономической безопасности государства.

Высокая степень возникающих рисков стала причиной изменения как валютной, так и географической структуры международных резервов. Банк России постепенно избавляется не только от долларовых активов как от инструмента резервирования, но и от американских финансовых институтов как от географического региона хранения золотовалютных резервов.

Согласно данным регулятора, по состоянию на конец 2017 года Соединенные Штаты занимали доминирующую позицию в географии распределения резервных активов с показателем $31 \%$. Но спустя два года ситуация кардинально поменялась: доля США снизилась до 8,4\%, уступив хранилищам золотого запаса в России (20\%), а также накоплениям на территории Франции, Германии, Китая и Японии (Рис. 4).

По мнению некоторых экспертов, такое изменение структуры золотовалютных резервов Российской Федерации с экономической точки зрения является неоптимальным. Их позиция основывается на ухудшении кредитного качества резервного портфеля из-за сокращения доли наиболее ликвидной и стабильной валюты - доллара США - и перемещения активов в более рискованные и волатильные инструменты.
Деятельность Банка России по диверсификации международных резервов посредством вложения в активы, деноминированные в юанях, оказалась убыточной. Втрое увеличив инвестиции в китайскую валюту, регулятор потерял порядка 20 млрд. долл. США на курсовых разницах из-за ее девальвации, даже несмотря на то, что доходность юаня в два раза больше доллара США [6].

Кроме того, подвергается критике и политика российских денежных властей по излишнему накоплению золотовалютных резервов из-за высоких альтернативных издержек их хранения. Считается, что вложение средств в инвестиции в том размере, в котором они накапливаются в составе резервов с минимальной доходностью, обеспечило бы больший экономический и социальный эффект (например, налоговые отчисления в бюджет или создание дополнительных рабочих мест для населения).

Вместе с тем, опыт предшествующих лет показывает, что «подушка безопасности» в виде международных резервов значительно влияет на устойчивость экономики. Большой объем резервного портфеля страны уменьшает риск дефолта по внешним обязательствам в случае неблагоприятных изменений мировой конъюнктуры, снижает волатильность и вероятность резких колебаний курса национальной валюты. Поэтому главная проблема, возникающая при управлении золотовалютными резервами, состоит в обеспечении эффективности их использования, что, в свою очередь, требует от органов денежно-кредитного регулирования анализа и выработки конструктивных решений по основным направлениям проводимой экономической политики, с учетом баланса между критериями надежности, прибыльности и ликвидности резервных активов.

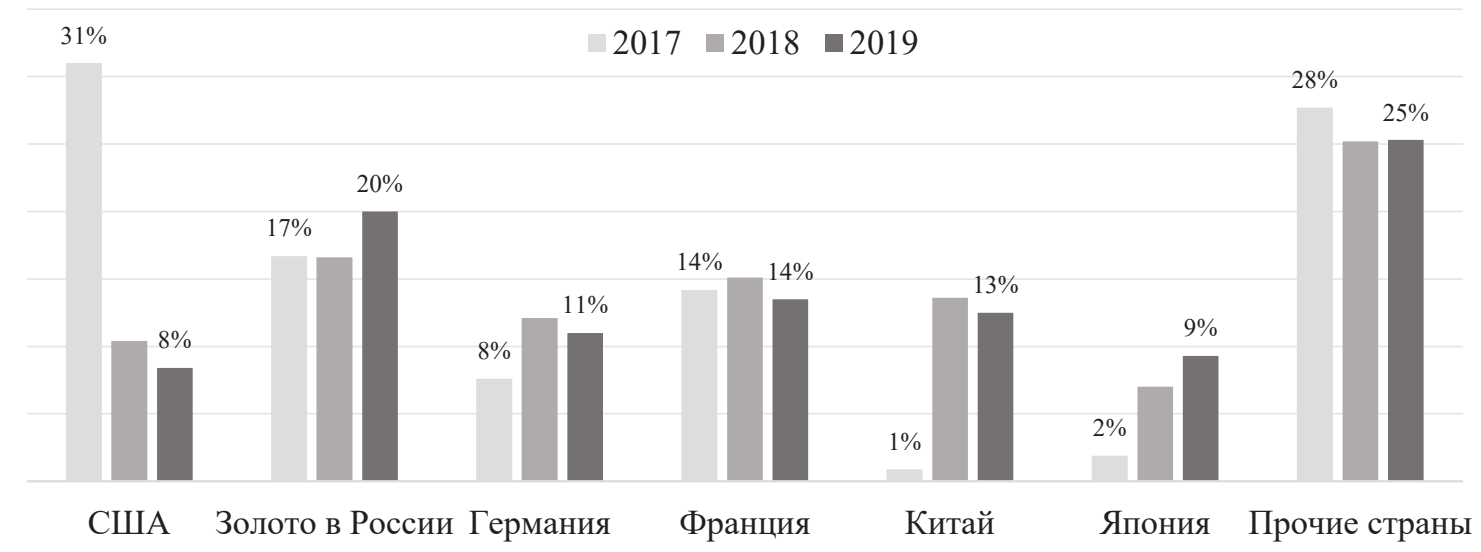

Puc. 4. Географическое распределение международных резервов России Источник: построено автором по данным Центрального банка Российской Федерации. 


\section{Библиографический список}

1. Валютные резервы и экономический рост. Почему США добиваются ревальвации юаня, и нужен ли России сильный рубль / Попов В. В. // Русский Журнал.-16.09.2003. http://old.russ.ru/politics/research/20030916-polt. html\#1b;

2. Золотовалютные резервы России достигли максимума с 2014 года / Г. Тадтаев, Г. Дубов // РБК. - 08.04.2019. URL: https://www.rbc.ru/economics/ 08/04/2019/5cab99ab9a7947f530e0f901;

3. Леонтьева Е.А., Наркевич С.С. Оптимальная практика создания и управления золотовалютными резервами / РАНХиГС, Москва.- 2015. URL: https://pps.ranepa.ru/Publication2/2015/5aaf5dd2-c9bf-e611-80d0005056a06105/55 9a54b87e2ce.pdf;

4. Международные резервы Российской Федерации / Центральный банк Российской Федерации. URL: http:// www.cbr.ru/hd_base/mrrf/mrrf_7d/;

5. Международные резервы РФ вернулись на докризисный уровень сентября 2008 года // Интерфакс.07.02.2020. URL: https://www.interfax.ru/ business/694503;

6. Обзор деятельности Банка России по управлению активами в иностранных валютах и золоте за 20192020 гг. / Центральный банк Российской Федерации. URL: http://www.cbr.ru/analytics/exchange-gold-report/ exchange-gold-report/\# highlight=обзор\%7Сдеятельности;

7. Последняя надежда / В. В. Попов, В. М. Полтерович // Эксперт. - № 48. - 22.12.2002. URL: https://pages.nes.ru/ vpopov/documents/RESERVES-last\%20 hope\%20with\%20charts.pdf;

8. Россия увеличила экспорт золота в 2019 году в 8,4 раза // РИА Новости.- 28.02.2020. URL: https://ria. ru/20200228/1565341128.html;

9. Руководство по платежному балансу и международной инвестиционной позиции / Вашингтон, округ Колумбия: Международный Валютный Фонд, пер. на русский.-2012.- 463 c. URL: https://www.imf.org/ external/russian/ pubs/ft/bop/2007/bopman6r.pdf;

10. Currency Composition of Official Foreign Exchange Reserves / Международный валютный фонд. URL: http:// data.imf.org/regular.aspx?key $=41175$;

11. Data Template on International Reserves and Foreign Currency Liquidity / Международный валютный фонд. URL: https://data.imf.org/?sk=2DFB3380-3603-4D2C-90BE-A04D8BBCE237;

12. Monthly central bank statistics / The World Gold Council. URL: https:/www.gold.org/goldhub/data/monthlycentral-bank-statistics;

13. The international role of the euro / European Central Bank. June 2019. URL: https://www.ecb.europa.eu/pub/ire/ html/ecb.ire201906 f0da2b823e.en.html\#toc22;

14. The World Bank Group. URL: https://data.worldbank.org/. 